\title{
A Comparative Study of Science Achievement and Self-concept during a Historical Transition
}

\author{
Jianjun Wang \\ Ph.D, Professor, Department of Advanced Educational Studies \\ School of Social Sciences and Education, California State University, Bakersfield \\ CA 93311-1099, USA \\ Tel: 1-661-654-3048 E-mail: jwang@csub.edu
}

Received: February 28, 2011 Accepted: March 2, 2011 Published: February 1, 2012

doi:10.5539/ies.v5n1p137 URL: http://dx.doi.org/10.5539/ies.v5n1p137

\begin{abstract}
Cross-cultural changes were accompanied by the sovereignty transition of Hong Kong during the TIMSS data collection, which triggered migration of intellectual families between Hong Kong and other places. To enhance comparability of the urban setting, this investigation focuses on Singapore and Hong Kong for having similar Chinese majority and colonial history. As both cities were reported having high student performance in science, student self-concept is articulated to examine its reciprocal relationship with science achievement under the context of non-monotonic population transition. The perspectives of comparative education have been gained through the cross-cultural understanding of empirical findings from the trend data analysis.
\end{abstract}

Keywords: Comparative research, Self-concept, Science Achievement

\section{Introduction}

It is generally believed that a positive self-concept contributes to enhancement of student motivation toward attainment of high academic achievement (Marsh, Hau, \& Kong, 2002; Harter, 1981). The achievement improvement further supports development of student positive self-concept. This mutual reinforcement has been theorized in a reciprocal relation model (e.g., Marsh, 1990; Shen \& Pedulla, 2000).

The Trend in Mathematics and Science Study (TIMSS) was first administered in 1995, and every 4 years thereafter. In 1995, forty-one nations participated in the study (Beaton et al., 1997; Martin, Mullis, Gonzalez, \& Chrostowski, 2004; Mullis et al., 2000). Whereas this model seemed globally generalizable in the western literature, researchers have been bewildered by following findings:

Within-country data generally show a positive relationship between student achievement and self-perceived competence in mathematics and science. However, when one examines this relationship between countries, the opposite relationship occurs, i.e. countries with higher student self-evaluations usually performed poorly on the TIMSS tests and vice versa. (Shen \& Pedulla, 2000, p. 237)

Given the contextual disparities among the participating countries, incomparability could be an issue behind the cross-cultural data analyses. Therefore, control of the confounding variables is needed in pursuing meaningful interpretation of the empirical findings within the comparative context. Although no one singled out Hong Kong and Singapore for comparing the reciprocal relation model, the research literature has indicated that "Hong Kong and Singapore are really an ideal pair for comparison" (Bray \& Lee, 1997, p. 10). In this investigation, three waves of the TIMSS data from Hong Kong and Singapore are analyzed to examine the trend of science achievement and student self-concept over an eight-year span (1995-2003). Besides having the Chinese majorities, both cities experienced British colony histories in the last century. Instead of repeating the inconsistent findings from the past, the comparability consideration may reduce the impact of nuisance variables, and thus, resolve the inconsistency from the within- and between-country examinations reported in the literature (see Shen \& Pedulla, 2000).

\section{Theoretical Framework}

To model the best teaching practice, researchers are more interested in studies of the top performing countries, including Hong Kong, Japan, South Korea, and Singapore (see Shen, 2005). Nonetheless, Bracey (1997) questioned the value of comparing countries of different sizes, such as the U.S. and Singapore "with about the population of metropolitan Washington, D.C." (p. 656). The incomparability issue could hinder meaningful comparisons across 
the nations. For instance, Japan and South Korea are different from Singapore and Hong Kong for lacking the Chinese majority in their populations. Consequently, those two countries may have less exposure to the Confucius culture influence in history. In addition, Japan and South Korea do not have open ground borders with any other countries, which eliminate the commuting possibility to "outsource" poverty and low-achieving students to their surrounding countries, a complaint that has been brought up by critics against the high achievement scores of Singapore (Bracey, 1997).

In contrast, "If one is looking at the world as a whole, then Hong Kong and Singapore do appear to be twins" (Krause, 1988, p. S64). Since the initial announcement of the Sino-Britain agreement on Hong Kong's future in 1984, a profound issue behind the political transition was "the outmigration of doctors, bankers and other professionals in a large-scale brain drain" (Mondejar, 2001, p. 1). When people leave for political reasons, they are likely to choose a similar urban destination at a familiar and stable location. Overholt (2007) recollected, "As the handover drew close, panicky emigration was draining away Hong Kong's pool of talent. There was a vast exodus of Hong Kong people and companies to Singapore" (ף. 1).

Consequently, as the parental education level dropped in Hong Kong, Singapore recruited some of the intellectual families, and the TIMSS 1999 results demonstrated an increase of parental education level shortly after the handover (Figures 1 \& 2). Later on, Goldstein (1999) further noted that "The Chinese immigrants of the past few years, I heard a lot of them say that they will return to Hong Kong ..." (p. 116). The non-monotonic population migration has resulted in reverse of the parental education changes between Singapore and Hong Kong in 2003 (Figures 1 \& 2).

Insert Figures $1 \& 2$ here.

In the past, however, research findings in this area were generated from small-scale case investigations. It was reported that American students usually demonstrated a combination of higher self-perception and poorer performance, while opposite was true for their counterparts from the East Asia (Stevenson, Lee, \& Stigler, 1986; Stevenson \& Stigler, 1992; Stigler, Smith, \& Mao, 1985; Uttal, Lummis, \& Stevenson, 1988). If the reciprocal relationship remains positive for American students, a different relation pattern might appear for their peers from the East Asia. Although the academic self-concept is not culture-specific, Bond and Cheung (1983) observed, "There has been remarkably little research on the self-concept done in cultures outside of the North American and North European axis" (p. 168). Built on the existing research result, large-scale data analyses are needed in this study to examine the reciprocal relationship in a cross-cultural context.

\section{Research Questions}

The cross-cultural change was triggered by the historical handover of Hong Kong during the TIMSS data collection, which demonstrated migration of intellectual families between Hong Kong and other places across an eight-year span (1995 - 2003). When the TIMSS database was first collected in 1995, Hong Kong was a British colony. The TIMSS 1999 and 2003 data were gathered after Hong Kong's handover in 1997. On basis of this trend data collection, this comparative study has been conducted to address the following research questions:

i. How does the non-monotonic change of parental education relate to development of student self-concept and science achievement in Hong Kong and Singapore?

ii. What are the relationship patterns between self-concept and science achievement in those twin cities?

iii. Has the statistical modeling been supported by the TIMSS 1995, 1999, and 2003 databases from Hong Kong and Singapore across the 8-year period?

\section{Methods}

Given the trend data from Hong Kong and Singapore, comparisons can be made between the twin cities across the time dimension. To guide examination of the reciprocal relation model, theoretical framework and empirical evidence have been gathered to support statistical analyses of the TIMSS databases.

\subsection{Theoretical Framework}

A two-point framework has been identified in the research literature to guide disentanglement of self-concept: (1) intra-individual comparisons (internal frame of reference), in which students assessed their own achievements in one subject with their achievements in other subjects; and (2) social comparisons (external frame of reference), in which students associated their achievements with those of their classmates (see Marsh, 1990; Shavelson, Hubner, \& Stanton, 1976). Thus, students not only actively pursue academic achievement, but also passively endure the social comparisons. In this investigation, both "I"- and "me"-perspectives of self-concept have been incorporated to indicate "self-as-doer" and "self-as-object", which conforms to a research convention over 100 years (Cooley, 1902; 
James, 1890).

Under the internal frame of reference, a person's science self-concept refers to a person's perception or belief in their ability to do well in science (Wilkins, 2003). Feasibility of disentangling this aspect of self-concept has been partially demonstrated by Wilkins' (2004) analysis of the TIMSS database. Besides excluding TIMSS 2003 data in Wilkins' (2004) investigation, the partiality also links to his use of a single item to represent self-concept - an approach yet to fit the two-point framework in the literature (see Cooley, 1902; James, 1890; Marsh, 1990; Shavelson, Hubner, \& Stanton, 1976). Since "individuals are capable of forming biased (optimistic or pessimistic) appraisals of their competence" (Martin \& Debus, 1998, p. 518), this study further incorporates the external frame of reference using the following item from the TIMSS 1999 and 2003 projects, "Science is more difficult for me than for others", to portray self-concept from an object perspective, reflecting students' feeling of relative difficulty in science learning. In the TIMSS 1995 questionnaire, this item was worded reversely to indicate whether science was relatively easy for a student. To maintain consistency in the result interpretation, the scale has been transformed so that a "strongly agree" response corresponds to a lower difficulty perception, and thus, a better self-concept.

\subsection{Empirical Evidence}

In assessing the academic achievement, TIMSS researchers have divided the science items into test booklets to reduce student testing burden. Because each student took only a subset of the test, a total of five plausible scores have been imputed to estimate the overall student achievement (Wang, 2001). It has been suggested that the results from the five plausible scores be averaged for statistical reporting to decrease uncertainty from the multiple score imputations (http://isc.bc.edu/timss1999i/pdf /T99_TR_CChap14.pdf). In this investigation, the five plausible scores from TIMSS 1995, 1999, and 2003 projects are employed to indicate student science achievement. The use of multiple indicators is designed to achieve a better representation of the latent variable (Schumacker \& Lomax, 1996).

The statistical method employed in this study is called Structural Equation Modeling (SEM). The SEM analysis is handled by a computer software package of the Linear Structure Relation (LISREL) (Jöreskog, Sörbom, Toit, \& Toit, 2000). More importantly, the LISREL software can model the relationship using indicators on an ordinal scale (Jöreskog, 1990), such as the ones involved in the self-concept identification. According Garson (2005), "The representation of latent variables based on their relation to observed indicator variables is one of the defining characteristics of SEM" (p. 3).

Insert Figure 3 here

The model of relationship between student self-concept and science achievement has been depicted in Figure 3 to reflect the context of parental education levels in Hong Kong and Singapore. Path coefficients $\left(\gamma_{1} \& \gamma_{2}\right)$ are estimated to assess linkages from parental education to student self-concept and science achievement, respectively (Question 1). Correlation coefficient ( $\beta$ ) has been computed by the LISREL software to assess the reciprocal relationship between self-concept and science achievement (Question 2). The model-fitting indices are calculated to examine the model reconfirmation by the TIMSS 1995, 1999, and 2003 databases (Question 3). To keep Figure 3 more readable, measurement errors considered in this study are not portrayed along with factor loadings $(\lambda)$, path coefficients $(\gamma)$, and correlation coefficients $(\beta)$.

\section{Results}

The trend findings are tabulated for the TIMSS 1995, 1999, and 2003 projects within each city to sort the comparative results between Singapore and Hong Kong across the time dimension (Table 1). Besides the pattern of parental education (Figures $1 \& 2$ ), there is also a non-monotonic trend of factor loadings on the self-concept variable between the doer and subject aspects $\left(\lambda_{\mathrm{y} 6}\right.$ and $\left.\lambda_{\mathrm{y} 7}\right)$. The empirical study further reconfirms the approximate equivalency of the five plausible scores according to the original TIMSS design (Gonzalez \& Smith, 1997). As a result, the factor loading values $\left(\lambda_{\mathrm{y} 1}, \lambda_{\mathrm{y} 2}, \lambda_{\mathrm{y} 3}, \lambda_{\mathrm{y} 4}\right.$, and $\left.\lambda_{\mathrm{y} 5}\right)$ are almost identical within each of the TIMSS databases.

\section{Insert Table 1 here}

In addition, the parental influence seems stronger on academic achievement than on self-concept $\left(\gamma_{1}>\gamma_{2}\right)$. Between the twin cities, obeying parental authority could be deeply rooted in the totalitarian culture of Singapore. Bracey (2006) noted that "the last thing a totalitarian society like Singapore wants is a cadre of young people who question conventional wisdom" (p. 153). Consequently, parental advice is duly respected, and the path coefficients $\left(\gamma_{1}\right.$ and $\left.\gamma_{2}\right)$ show more parental influence on the Singapore side. The focus on parental education is important because "better-educated parents have children who score higher on tests" (Bracey, 1998, p. 629).

Based on the trend data, the statistical analysis has provided more empirical evidence to confirm the model fitness. In particular, goodness of fit indices (GFI) have been listed in Table 2 to indicate plausibility of fitting the reciprocal 
model (Figure 3) to the empirical data, and the root mean square errors of approximation (RMSEA) are computed to assess the average of residuals not accounted for by the model. The high GFI indices and small RMSEA values reconfirm the model fitness to the trend data from TIMSS. Although no strong reciprocal relationship has been found between science achievement and self-concept, the cross-cultural influence can be incorporated in interpreting the empirical findings during the period of historical transition.

Insert Table 2 here

\section{Discussion}

As was shown in the result section, the agreement in the reciprocal relationship was fairly consistet between Hong Kong and Singapore. Hence, this investigation did not repeat the inconsistency issue observed by Shen and Pedulla (2000) from large-scale international studies. In part, this was because of the comparability consideration in the twin city choice. Although Singapore and Hong Kong are not identical on every aspect, they are comparable in terms of the past colonial history and Chinese majority. The well-developed urban setting and relatively short distance further strengthens the linkage between the two sides, causing complementary fluctuations of parental education from the population migration during the handover. Due to the contextual change from the decolonization, the cross-cultural transition should be examined to disentangle the empirical differences between Hong Kong and Singapore.

\subsection{The Transition Difference}

The cultural change during the period of the TIMSS data coverage (1995-2003) seems to have set Singapore and Hong Kong on different paths. At the starting point, Hong Kong might have more western culture influence in 1995 as a British colony. Under the "one nation, two system" policy, the stability has been maintained in Hong Kong (Koo, Kam, \& Choi, 2003; Law, 1997). In contrast, "Singapore's political leaders have had to take care that Singapore is not seen as a "third China" (Tan, 1997, p. 303). The parental educational commitment not only represents the family cultural heritage, but also conforms to civic dedications of the urban community. Although both cities demonstrated more emphasis of parental influence on student academic preparation $\left(\gamma_{1}>\gamma_{2}\right)$, Singapore appeared to have a relatively larger gap between $\gamma_{1}$ and $\gamma_{2}$ (Table 1), which suggested stronger parental push on the academic side. This finding also confirmed the TIMSS reports that placed Singapore above Hong Kong in student science achievement (Beaton et al., 1997; Martin, Mullis, Gonzalez, \& Chrostowski, 2004; Mullis et al., 2000).

To maintain the metropolitan status, Singapore and Hong Kong must continue embracing the Western influence by incorporating English media in the government and legal systems, which seemed to have engendered a sense of inferiority among the local Chinese majority. "Set against this inferiority is pride in what are perceived as a great Chinese civilization" (Bruce, 1990, p. 10). The sovereignty handover has built a stage to promote the Chinese cultural influence in Hong Kong, and as a result, a higher factor loading was switched to the subject aspect of the self-concept from the TIMSS 1999 findings. The increase of Chinese cultural influence $\left(\lambda_{y 6}<\lambda_{y 7}\right)$ also happened in Singapore due to the influx of Chinese immigrants. Before and after the upsurge of Chinese cultural impact in the twin cities, the results from the TIMSS 1995 and 2003 projects showed a pattern of stronger influence from the doer perspective that positioned students as active learners $\left(\lambda_{y_{6}}>\lambda_{y_{7}}\right)$. With a high population density, Hong Kong and Singapore exemplify relative poverty of natural resources, which makes education an important endeavor for human resource development.

\subsection{Reciprocal Relationship}

Under the western culture influence, student self-concept and academic performance are expected to improve concurrently (Marsh, Hau, \& Kong, 2002). Nonetheless, Confucius stated that "The more a man learns, the more he knows his ignorance" (http://novel.jschina.com.cn/yingyuwenxue/yinghmy/yinghaaaanmingyan15.htm, p. 1). Consequently, students are discouraged from rating themselves highly on the self-concept (Leung, 2002). According to a meta-analysis conducted by Ma and Kishor (1997), the reciprocal relationship was reported strong and positive in the western literature. But one may expect a negative relationship influenced by the Chinese culture (Leung, 2002; Wang, Oliver, \& Staver, 2008). “The Chinese saying 'contendness leads to loss, humility leads to gain' illustrates the point well" (Leung, 2002, p. 106). Because of the co-existence of the East and West culture influences, weak correlations ( $\beta$ ) were obtained from the TIMSS data analysis (Table 1). The $\beta$ value changes on the time dimension also concurred to the stability maintained in Hong Kong and the decrease of Chinese culture influence in Singapore.

\subsection{Model Fitness}

The model fitness has been examined in each wave of the TIMSS data from the twin cities to match two components of this investigation: (1) a trend examination of the reciprocal relation model within Singapore and Hong Kong, and (2) a comparative analysis of the research findings between the twin cities. The results in Table 2 consistently 
demonstrated a high fitting plausibility $(\mathrm{GFI} \geq .97)$ and small unaccounted residuals (RMSEA $\leq .06)$ across the city and time settings. This finding reconfirmed no disparity of empirical results from the within- and between-city perspectives.

In summary, this investigation focuses on Hong Kong and Singapore for having similar urban settings to support an examination of student science achievement and self-concept. While Singapore has gained its independence several decades ago, Hong Kong's historical handover to China happened more recently in 1997. Built on an eight-year (1995-2003) TIMSS database, this study disentangled empirical differences in educational outcomes under the non-monotonic influence of parental education resulted from the political handover. Instead of involving inconsistent results from numerous unparalleled countries, the scope of this investigation has been intentionally limited within the twin cities to enhance comparability of the research outcomes. In this regard, the study only illustrated a different approach in comparative education. Although the control of confounding variables has been achieved through narrowing the research scope, it does not preclude selection of more countries to expand the empirical investigation in the future.

\section{References}

Bandura, A. (1986). Social foundation of thought and action: A social cognitive theory. Englewood Cliffs, NJ: Prentice-Hall.

Bandura, A. (1994). Self-efficacy. Encyclopedia of Human Behavior, 4, 71-81

Beaton, A., Martin, M., Mullis, I., Gonzalez, E., Smith, T., \& Kelly, D. (1997). IEA's third international mathematics and science report: Science achievement in the middle school years. Chestnut Hill, MA: TIMSS \& PIRLS International Study Center, Boston College.

Bond, M., \& Cheung, T. (1983). The effect of culture among respondents in Hong Kong, Japan, and the United States. Journal of Cross-Cultural Psychology, 14, 153-171. http://dx.doi.org/10.1177/0022002183014002002

Bracey, G. (1997). More on TIMSS. Phi Delta Kappan, 78, 656-57

Bracey, G. (1998). About those private school achievements. Phi Delta Kappan, 79, 629-30

Bracey, G. (2006). The $16^{\text {th }}$ Bracey report on the condition of public education. Phi Delta Kappan, 88, 151-66

Bracey, G. (2007). Test scores and economic growth. Phi Delta Kappan, 88, 554-56

Bray, M., \& Lee, W. O. (1997). Education and political transition: Themes and experiences in East Asia. Hong Kong: Comparative Education Research Centre

Brown, S., Lent, R., \& Larkin, K. (1989). Self-efficacy as a moderator of scholastic aptitude-Academic performance relationship. Journal of Vocational Behavior, 35, 64-75. http://dx.doi.org/10.1016/0001-8791(89)90048-1

Bruce, N. (1990). EL2-medium education in a largely monolingual society: The case of Hong Kong. Hong Kong Papers in Linguistics and Language Teaching, 13, 9-23

Cooley, C. (1902). Human nature and the social order. New York: Scribner.

Garson, G. (2005). Structural equation modeling. [Online] Available: http://www2.chass.ncsu.edu/garson/pa765/structur.htm (July 10, 2010).

Goldstein, T. (1999). Negotiating identities in Hong Kong, Canada: Opening small doors. Bilingual Research Journal, 23, 113-23

Gonzalez, E., \& Smith, T. (1997). Users guide for the TIMSS international database. Chestnut Hill, MA: TIMSS International Study Center.

Harter, S. (1981). A model of intrinsic mastery motivation in children: Individual differences and developmental change. In A. Collins (Ed), Minnesota Symposia on Child Psychology, pp. 215-55. Hillsdale, NY: Erlbaum.

James, W. (1890). Principles of psychology (Vol. 1). New York: Holt. http://dx.doi.org/10.1037/11059-000

Jöreskog, K. (1990). New developments in LISREL: Analysis of ordinal variables using polychoric correlations and weighted least squares. Quality and Quantity, 24, 387-404. http://dx.doi.org/10.1007/BF00152012

Jöreskog, K., Sörbom, D., Toit, S., \& Toit, M. (2000). LISREL 8: New statistical features. Chicago, IL: Scientific Software International.

Koo, R., Kam, M., \& Choi, B. (2003). Education and schooling in Hong Kong: Under one country, two systems. Journal of the Association for Childhood Education International, 79, 137-44 
Krause, L. (1988). Hong Kong and Singapore: Twins or kissing cousins? Economic Development and Cultural Change 36, [Supplement: Why does overcroweded, resource-poor east Asia succeed: Lessons for the LDCs?], pp. S45-S66

Law, W. (1997). The accommodation and resistance to decolonisation, neocolonisation and recolonisation of higher education in Hong Kong. Comparative Education, 33, 187-209. http://dx.doi.org/10.1080/03050069728523

Leung, F. (2002). Behind the high achievement of east Asian students. Educational Research and Evaluation: An International Journal on Theory and Practice, 8, 87-108

Locke, E., \& Latham, G. (1990). A theory of goal-setting and task performance. Englewood Cliffs, NJ: Prentice-Hall.

Ma, X., \& Kishor, N. (1997). Attitude toward self, social factors, and achievement in mathematics: A meta-analytic review. Educational Psychology Review, 9, 89-120. http://dx.doi.org/10.1023/A:1024785812050

Marsh, H. (1990). A multidimentional hierarchical self-concept theoretical and empirical justification. Educational Psychology Review, 2, 77-172. http://dx.doi.org/10.1007/BF01322177

Marsh, H., Hau, K., \& Kong, C. (2002). Multilevel causal ordering of academic self-concept and achievement: Influence of language of instruction (English compared with Chinese) for Hong Kong students. American Educational Research Journal, 39, 727-63. http://dx.doi.org/10.3102/00028312039003727

Martin, A., \& Debus, R. (1998). Self-reports of mathematics self-concept and educational outcomes: The role of ego-dimensions and self-consciousness. British Journal of Educational Psychology, 68, 517-35. http://dx.doi.org/10.1111/j.2044-8279.1998.tb01309.x

Martin, M., Mullis, I., Gonzalez, E., \& Chrostowski, S. (2004). Findings from IEA's Trends in International Mathematics and Science Study at the fourth and eighth grades. Chestnut Hill, MA: TIMSS \& PIRLS International Study Center, Boston College.

Michael, D. (2006). Hong Kong's lessons for U.S. education. Business Week Online [Online] Available: http://www.businessweek.com/globalbiz/content/nov2006/gb20061110_025651.htm (July 10, 2010).

Mondejar, R. (2001). The future is now: Hong Kong \& China in 1997. [Online] Available: http://www.cipe.org/publications/fs/ert/e06/9hongko.htm (July 10, 2010).

Mullis, I., Martin, M., Gonzalez, E., Gregory, K., Garden, R., O’Connor, K., Chrostowski, S., \& Smith, T. (2000). TIMSS 1999 international mathematics report: Findings from IEA's repeat of the Third International Mathematics and Science Study at the eighth grade. Chestnut Hill, MA: TIMSS \& PIRLS International Study Center, Boston College.

Multon, K., Brown, S., \& Lent, R. (1991). Relation of self-efficacy beliefs to academic outcomes: A meta-analytic investigation. Journal of Counseling Psychology, 38, 30-8. http://dx.doi.org/10.1037/0022-0167.38.1.30

Overholt, W. (2007). A decade later: Hong Kong's economy since 1997. [Online] Available: http://www.hkjournal.org/PDF/2007_fall/4.pdf (July 10, 2010).

Schumacker, R., \& Lomax, R. (1996). A beginner's guide to structural equation modeling. Mahwah, NJ: Lawrence Erlbaum.

Schunk, D. (1984). The self-efficacy perspective on achievement behavior. Education Psychologist, 19, 119-218. http://dx.doi.org/10.1080/00461528409529281

Schunk, D. (1989). Social cognitive theory and self-regulated learning. In Barry Zimmerman \& Dale Schunk (Eds.), Self-Regulated Learning and Academic Achievement: Theory, Research, and Practice, pp.83-110. New York,NY: Springer Verlag. http://dx.doi.org/10.1007/978-1-4612-3618-4_4

Schunk, D. (1991). Self-efficacy and academic motivation. Educational Psychologist, 26, 207-31. http://dx.doi.org/10.1207/s15326985ep2603\&4_2

Shavelson, R., Hubner, J., \& Stanton, G. (1976). Self-concept: Validation of construct interpretations. Review of Educational Research, 46, 407-441. http://dx.doi.org/10.3102/00346543046003407

Shen, C. (2005). How American middle schools differ from schools of five Asian countries: Based on cross-national data from TIMSS 1999. Educational Research and Evaluation, 11, 179-199. http://dx.doi.org/10.1080/13803610500110810

Shen, C., \& Pedulla, J. (2000). The relationship between students' achievement and their self-perception of competence and rigor of mathematics and science: A cross-national analysis. Assessment in Education, 7, 237-53. http://dx.doi.org/10.1080/713613335 
Stevenson, H., \& Stigler, J. (1992). The learning gap. New York: Simon \& Schuster.

Stevenson, H., Lee, S., \& Stigler, J. (1986). Mathematics achievement of Chinese, Japanese, and American children. Science, 231, 693-99. http://dx.doi.org/10.1126/science.3945803

Stigler, J., Smith, S., and Mao, L. (1985). The self-perception of competence by Chinese children. Child Development, 56, 1259-70. http://dx.doi.org/10.2307/1130241

Tan, J. (1997). Education and colonial transition in Singapore and Hong Kong: Comparisons and contrasts. Comparative Education, 33, 303-312. http://dx.doi.org/10.1080/03050069728587

Uttal, D., Lummis, M., \& Stevenson, H. (1988). Low and high mathematics achievement in Japanese, Chinese, and American elementary-school children. Developmental Psychology, 24, 335-42. http://dx.doi.org/10.1037/0012-1649.24.3.335

Wang, J. (2001). TIMSS primary and middle school data: Some technical concerns. Educational Researcher, 30, 17-21. http://dx.doi.org/10.3102/0013189X030006017

Wang, J., Oliver, S., \& Staver, J. (2008). Self-concept and science achievement: Investigating a reciprocal relation model across the gender classification in a cross-cultural context. Journal of Research in Science Teaching, 45, 711-25. http://dx.doi.org/10.1002/tea.20182

Wilkins, J. (2003). The relationship between mathematics and science self-concept and related achievement: An international investigation. Paper presented at the annual meeting of the American Educational Research Association, Chicago, IL.

Wilkins, J. (2004). Mathematics and science self-concept: An international investigation. Journal of Experimental Education, 72, 331-46. http://dx.doi.org/10.3200/JEXE.72.4.331-346

Wong, T. (2005). Comparing state hegemonies: Chinese universities in postwar Singapore and Hong Kong. British Journal of Sociology of Education, 26, 199-218. http://dx.doi.org/10.1080/0142569042000294174 
Table 1. Comparison of parameter estimates in the science model between Hong Kong (HK) and Singapore (SGP)

\begin{tabular}{|c|l|l|l|l|l|l|}
\hline Parameter & \multicolumn{2}{|l}{ TIMSS 1995 } & \multicolumn{2}{l}{ TIMSS 1999 } & \multicolumn{2}{l}{ TIMSS 2003 } \\
\hline Estimates & HK & SGP & HK & SGP & HK & SGP \\
\hline Factor pattern coefficients & & & & & & \\
\hline$\lambda_{\mathrm{y} 1}$ & 0.93 & 0.89 & 0.85 & 0.93 & 0.94 & 0.97 \\
\hline$\lambda_{\mathrm{y} 2}$ & 0.93 & 0.89 & 0.87 & 0.94 & 0.94 & 0.97 \\
\hline$\lambda_{\mathrm{y} 3}$ & 0.93 & 0.90 & 0.87 & 0.92 & 0.93 & 0.97 \\
\hline$\lambda_{\mathrm{y} 4}$ & 0.93 & 0.89 & 0.87 & 0.93 & 0.94 & 0.97 \\
\hline$\lambda_{\mathrm{y} 5}$ & 0.93 & 0.89 & 0.87 & 0.93 & 0.93 & 0.97 \\
\hline$\lambda_{\mathrm{y} 6}$ & 1.10 & 6.40 & 0.48 & 0.56 & 0.75 & 0.82 \\
\hline$\lambda_{\mathrm{y} 7}$ & 0.36 & 0.05 & 0.78 & 0.76 & 0.53 & 0.59 \\
\hline$\lambda_{\mathrm{x} 1}$ & 0.77 & 0.74 & 0.62 & 0.73 & 0.75 & 0.78 \\
\hline$\lambda_{\mathrm{x} 2}$ & 0.85 & 0.75 & 0.72 & 0.61 & 0.82 & 0.84 \\
\hline$\gamma_{2}$ & & & & & & \\
\hline$\gamma_{1}$ & 0.02 & 0.01 & 0.72 & 0.61 & 0.02 & 0.09 \\
\hline Reciprocal relation & 0.19 & 0.37 & 0.19 & 0.36 & 0.15 & 0.40 \\
\hline$\beta$ & 0.12 & 0.02 & 0.14 & 0.22 & 0.13 & 0.22 \\
\hline Path coefficients & & & & & & \\
\hline & & & & & \\
\hline
\end{tabular}

Table 2. Model fitting indices for the TIMSS and TIMSS-R databases between Hong Kong (HK) and Singapore (SGP)

\begin{tabular}{|c|c|c|c|c|c|c|}
\hline Fitness & \multicolumn{2}{|c|}{$\underline{\text { TIMSS } 1995}$} & \multicolumn{2}{|c|}{ TIMSS 1999} & \multicolumn{2}{|c|}{ TIMSS 2003} \\
\hline Indices & & SGP & HK & SGP & HK & SGP \\
\hline $\begin{array}{l}\text { Root Mean Square Error of } \\
\text { Approximation (RMSEA) }\end{array}$ & 0.04 & 0.03 & 0.06 & 0.06 & 0.05 & 0.03 \\
\hline Goodness of Fit Index (GFI) & 0.99 & 0.99 & 0.97 & 0.98 & 0.98 & 0.99 \\
\hline
\end{tabular}




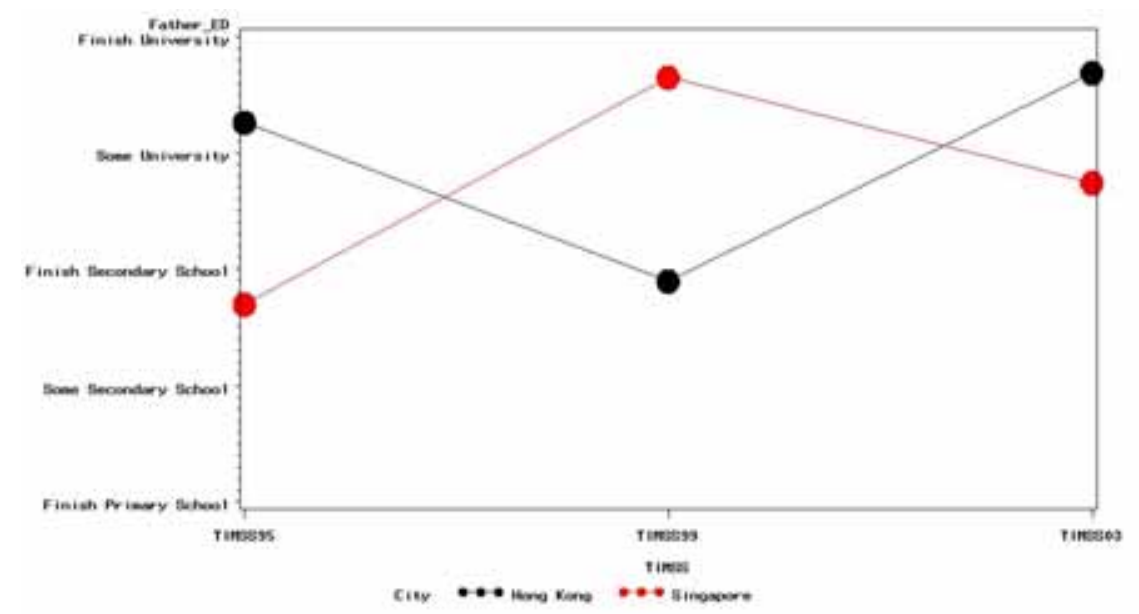

Figure 1. Comparison of father education levels between Hong Kong and Singapore

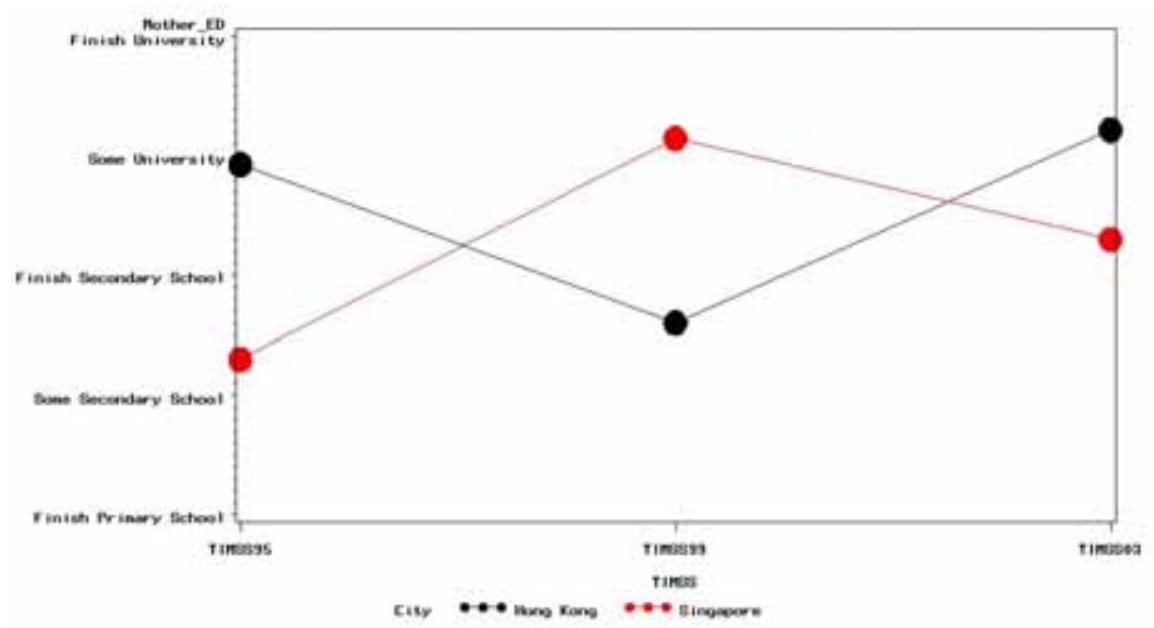

Figure 2. Comparison of mother education levels between Hong Kong and singapore 


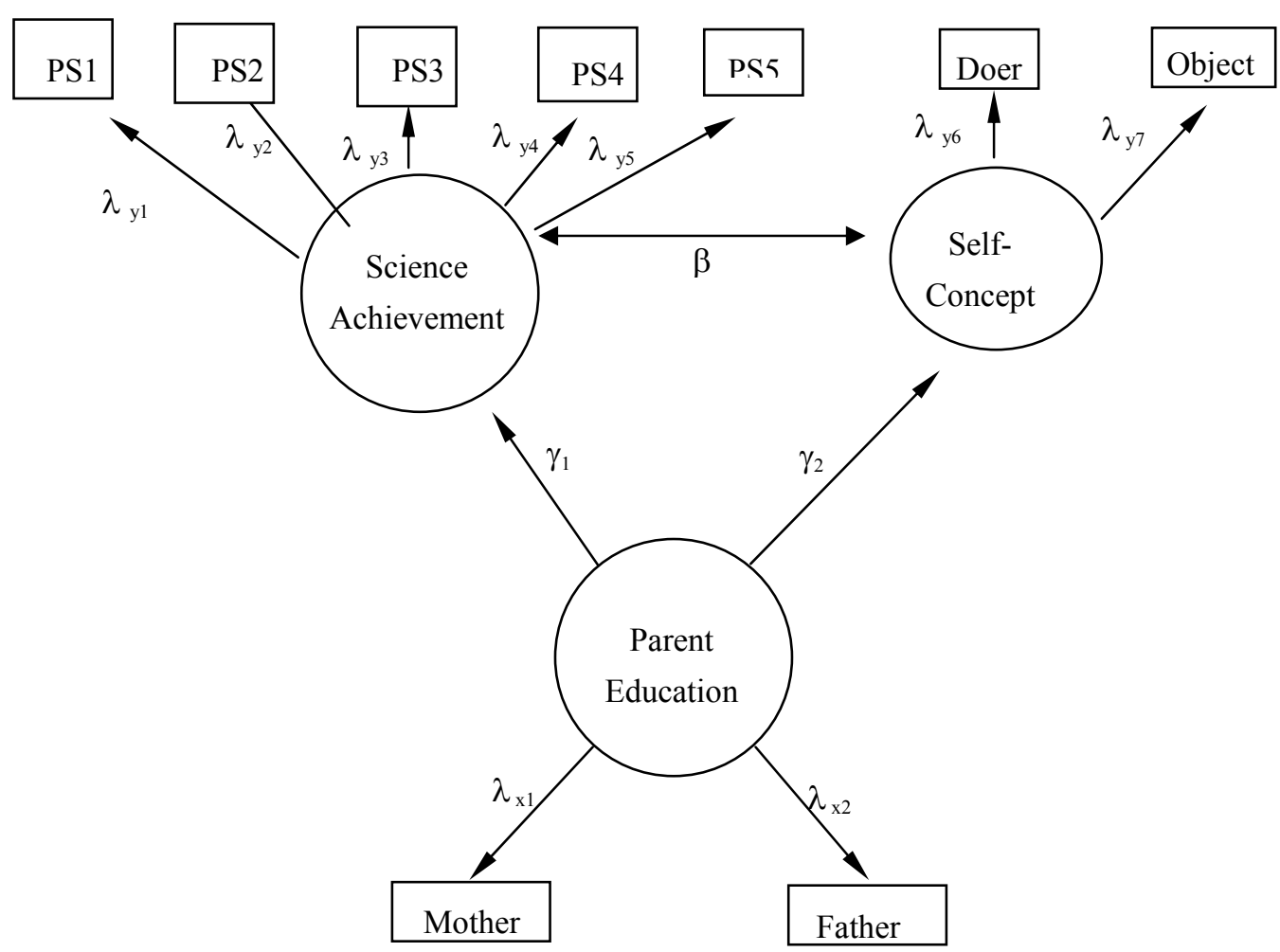

Figure 3. A Structural Model of Science Achievement and Self-Concept from TIMSS

\section{Notes}

1. PS1, ... PS5 are plausible science scores imputed from TIMSS projects.

2. The "doer" indicator is based on student responses on whether they do well in science. The "object" indicator is based on students' responses on whether "science is more difficult for me than for others."

3. Indicators for the "Parental Education" factor are based on father and mother levels of education. 